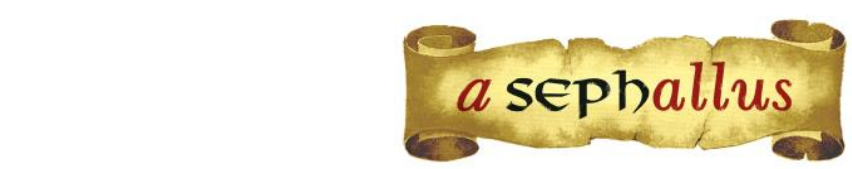

Revista aSEPHallus de Orientação Lacaniana ISSN $1809-709 X$

Núcleo Sephora de Pesquisa sobre o Moderno e o Contemporâneo

Reconfigurações do narcisismo entre profissionais de saúde contemporâneos: o que o estudo psicanalítico sobre o Burnout tem a nos dizer sobre isso?

Lucia Helena Carvalho dos Santos Cunha Doutora em teoria psicanalítica pelo Programa de Pós-Graduação em Teoria Psicanalítica do Instituto de Psicologia da UFRJ Psicanalista atuando no Hospital das Clínicas de Teresópolis Constantino Ottaviano/FESO, Professora adjunta do Centro Universitário Serra dos Órgãos, em Teresópolis/RJ

E-mail: luciahelenacunha@gmail.com

Resumo: Esse artigo interroga os efeitos das reconfigurações narcísicas contemporâneas do comportamento profissional. O estudo psicanalítico do burnout entre médicos traz subsídios sobre mudanças, nos dias de hoje, da mentalidade que sempre exigiu desses sujeitos renúncia ao gozo imediato de seus interesses particulares, em prol do ideal de cura. O caráter e o comportamento ético, nestas condições, necessitam da sublimação como um destino pulsional importante para a regulação dessa economia de gozo. O sintoma profissional em questão indica um fracasso deste arranjo tradicional, levantando questões sobre as consequências subjetivas da transformação contemporânea da saúde numa mercadoria.

Palavras-chave: narcisismo; burnout; sublimação; caráter; contemporaneidade.

Réconfigurations de narcissisme chez les professionnels de la santé contemporaine: qu'est-ce que l'étude psychanalytique de Burnout a à dire à ce sujet

Cet article interroge les effets des reconfigurations narcissiques contemporaines du comportement professionnel. L'étude psychanalytique de l'epuisement professionnel chez les medicins fournit des informations sur des changements, ces jours-ci, d'une mentalité qui a toujours exigé a ces sujets le renoncement à la juissance immédiate de leurs intérêts privés, par souci d'un ideal de guérison. Le caractère et le comportement éthique dans ces conditions ont besoin de la sublimation comme une destination importante pour la régulation pulsionnelle dans cette économie de jouissance. Le syntôme professionnel em question indique um échec de cette arrangement traditionnel, soulevant des questions sur les effets subjectifs de l'utilisation contemporaine de la santé comme une marchandise.

Mots-clés: narcissisme; épuisement professionnel; sublimation; caractère; contemporanéité.

\begin{abstract}
Reconfigurations of narcissism among contemporary health professionals: what a psychoanalytical study on Burnout has to tell us about it?

This article questions the effects of contemporary narcissistic reconfigurations of professional behavior. The psychoanalytic study of Burnout Syndrome among physicians brings about subsidies on today's changes in the mentality that has always demanded from these subjects a resignation of the immediate enjoyment of their particular interests, in favor of an ideal of healing. Character and ethical and behavior, in these conditions, need sublimation as an important drive destination for the regulation of this enjoyment economy. The professional symptom in question indicates a failure of this traditional arrangement, raising questions about the subjective consequences of the contemporary transformation of health into a commodity.
\end{abstract}

Keywords: narcissism; burnout, sublimation; character; contemporaneity. 


\title{
Reconfigurações do narcisismo entre profissionais de saúde contemporâneos: o que o estudo psicanalítico sobre o Burnout tem a nos dizer sobre isso? ${ }^{1}$
}

\author{
Lucia Helena Carvalho dos Santos Cunha
}

\section{Introdução}

A sublimação pode responder ao império contemporâneo dos objetos, das imagens e da lei do mercado? Essa pergunta foi levantada por Coelho dos Santos (2016) e endereçada ao grupo de pesquisa sobre as reconfigurações do narcisismo na contemporaneidade, e servirá de eixo condutor neste artigo. Pretendo demonstrar os efeitos sintomáticos que a redução dos ideais, associada a novas configurações do narcisismo, estão produzindo sobre o comportamento de sujeitos em sua relação com a profissão. Em especial, aqueles que tradicionalmente adotavam uma posição subjetiva com valores alteritários, voltados para os interesses comunitários, valendo-se do destino sublimatório para exercer profissões na área da saúde, dentre as quais a medicina.

A partir da pesquisa que venho desenvolvendo sobre um sintoma profissional contemporâneo, que está em expansão nos dias de hoje, nomeadamente o Burnout, recolhi evidências que podem contribuir para o eixo da questão. O referido sintoma (Carlotto \& Câmara, 2008) se manifesta, entre outros aspectos, por alterações físicas e mentais, das quais se destaca a perda da realização profissional, podendo provocar o abandono da profissão. Ou seja: perda radical da possibilidade de satisfação no exercício da profissão. Em geral, os sujeitos afetados por este sintoma são encontrados principalmente entre os que escolheram profissões ditas vocacionais: médicos, enfermeiros, professores, cuja ética exige grande respeito e dedicação ao outro.

\section{Sobre a sublimação}

Lanço uma pergunta: estaria em jogo uma reconfiguração narcísica entre sujeitos contemporâneos que afetaria a capacidade de sublimação, necessária ao exercício destas profissões? Freud inscreve a sublimação na raiz do sentimento ético, como um destino pulsional cuja satisfação - em função da plasticidade da pulsão - se dá de uma maneira especial, socialmente valorizada, através de um desvio da meta sexual em detrimento da satisfação totalmente narcísica. Tal desvio, capaz de elevar a realização pulsional a um nível ético e estético, permite ao sujeito um tipo de realização útil à civilização. A capacidade de amor objetal, direcionando a libido para fora do eu, estrutura uma organização psíquica necessária ao funcionamento social, e depende da sublimação. Freud diz claramente: "O ideal do Eu requer a sublimação, embora não possa força-la" (Freud, 1914/2010, p. 41).

A sublimação, enquanto um destino pulsional alternativo ao recalque, leva por outras vias o sujeito a encontrar um tipo de satisfação diferenciada daquela alcançada pelo sintoma. Como a resposta subjetiva do Burnout se configura como um sintoma, podemos considerar que a satisfação pulsional tomou o caminho do recalque, e que o sujeito não encontrou as condições necessárias 
para fazer uso da sublimação necessária ao cumprimento das exigências éticas e sociais de sua profissão. Um outro aspecto que será levado em consideração é a formação do caráter. Freud anunciou em um texto de 1908, ter encontrado três características de comportamento relacionadas à transfiguração do erotismo anal: pessoas ordeiras, parcimoniosas e obstinadas se comportam assim a partir da formação reativa, que impulsiona a reversão da disposição infantil universalmente perversa em virtudes sociais. Freud considera a formação reativa como uma "subvariedade da sublimação", que começa no período de latência e, nos casos mais favoráveis, prossegue por toda vida. E acrescenta:

Aquilo a que chamamos de caráter de um homem se constrói, numa boa medida, a partir do material das excitações sexuais, e se compõe de pulsões sexuais fixadas desde a infância, de outras obtidas por sublimação, e de construções destinadas ao refreamento eficaz de moções perversas, inutilizáveis (Freud, 1905/1980, p. 246).

Voltaremos ao tema do caráter mais adiante. Prosseguimos abordando a sublimação, com Lacan, como a elevação de um objeto de satisfação à dignidade da Coisa, das Ding, objeto causa do desejo - aqui, no caso, o desejo profissional.

$\mathrm{O}$ arranjo psíquico tradicionalmente encontrado em sujeitos que dedicam suas vidas à missão de cuidar da saúde alheia implica em uma posição altruísta, de doação de si, dedicando seu tempo, sua atenção e empenho na recuperação da saúde de seu paciente, numa entrega a uma causa. Esta posição se faz a partir da capacidade sublimatória, que eleva a atenção à saúde alheia à dignidade de das Ding.

A formação de um caráter altruísta supõe a regulação pulsional pelo ideal do eu, a cessão de uma parcela do gozo narcísico em prol da aceitação de exigências advindas de necessidades alheias. Mesmo que, nos médicos, esse gozo seja recuperado fantasmaticamente numa cena onde seu paciente se torna devedor de reconhecimento e gratidão, podemos supor que o funcionamento pulsional foi submetido a um desvio, cujo percurso exigiu uma parcela de sacrifício e de trabalho, antes de alcançar o alvo da satisfação. O fantasma de onipotência frequentemente sustenta o desejo do médico num arranjo onde o sujeito encontra satisfação profissional através da realização pela via sublimatória.

Assim, através da sublimação, consideramos que o sujeito encontra um tipo particular de satisfação que lhe permite obter realização pessoal em profissões voltadas para o bem-estar da população, como as que promovem a saúde e a educação de um povo. Exatamente as profissões onde mais se encontra a queixa de Burnout.

\section{Narcisismo X Ideal do eu}


Minha pesquisa verificou que alterações no comportamento social e ético estão ocorrendo na atuação profissional de sujeitos que exercem a medicina, introduzindo uma mudança na mentalidade que orienta a relação dos sujeitos com sua profissão e com seus colegas de trabalho (Cunha, 2015; Coelho dos Santos \& Cunha, 2013). As evidências, que serão abaixo descritas, confirmam a observação de vários psicanalistas sobre um predomínio do funcionamento narcísico entre sujeitos contemporâneos. Essa característica vem produzindo efeitos na formação do caráter, conforme verificado por Coelho dos Santos e Azeredo (2005).

As profissões da área de saúde, em especial a medicina e a enfermagem, requerem sujeitos capazes de suportarem horários extensos de trabalho lidando com o sofrimento alheio, com a perda de horas de sono, lazer, convívio com familiares, em detrimento de jornadas reguladas pelo descanso e com menor nível de responsabilidade e estresse. A pesquisa em curso verificou o surgimento de um novo padrão de conduta profissional, que não era comum entre as gerações anteriores: um novo contingente de profissionais recusa fazer concessões inerentes a essas condições. Evita plantões aos fins de semana, na periferia ou longe de grandes centros urbanos, e prefere escolher especialidades com menor contato direto com pacientes. Quando não exige salários mais altos, impõe condições diferenciadas de trabalho - para não falar dos que fazem de sua atividade um negócio lucrativo, revelando um perfil mercenário (Cunha, 2015). Da mesma forma, filósofos, sociólogos e psicanalistas constatam que em nosso admirável mundo novo, os valores sociais, morais e éticos, sofreram grande transformação. Nas palavras de Coelho dos Santos: "Estamos diante de uma nova moralidade, que não se orienta mais pelos ideais, e sim pelo objeto de satisfação" (Coelho dos Santos, 2008, p. 69).

É essa constatação que me permite discutir aqui a hipótese de uma redução da capacidade sublimatória entre esses sujeitos, uma vez que o destino pulsional da sublimação exige capacidade de renúncia à satisfação imediata e direta da pulsão, num esforço que não vem sendo estimulado pela ideologia dominante nos tempos atuais. Muito pelo contrário, o empuxo ao consumo, que caracteriza o funcionamento da economia neoliberal, estimula a pleonexia (Dufour, 2015) e um imediatismo nas exigências de satisfação e induz a um regime de gozo onde a desregulação pulsional deixa visível a marca do excesso.

\section{Mudanças na contemporaneidade}

Nossos tempos se caracterizam pela queda dos ideais e pela busca incessante da felicidade. Nas palavras de Lipovetsky:

\footnotetext{
Pela primeira vez estamos diante de uma sociedade que, longe de exaltar a observância dos preceitos superiores, faz deles um uso eufêmico e os lança ao descrédito, deprecia o ideal da abnegação mediante o estímulo sistemático à satisfação das aspirações imediatas, à paixão do ego, à felicidade intimista e materialista (Lipovetsky, 2005, p. xxxviii).
} 
A profissão médica, cercada por múltiplas idealizações em torno da figura do médico, mostrase mais propícia à produção do desencanto, uma vez que o Outro contemporâneo não sustenta mais a crença em antigos valores e ideais. Durante séculos, a sociedade reverenciou a natureza sagrada da profissão médica por sua proximidade com os mistérios da vida e da morte, e demonstrou sua admiração pelos que abdicavam de sua vida pessoal em prol do trabalho junto a pobres, doentes ou moribundos, pela nobreza de caráter desses sujeitos. Na Grécia antiga, por exemplo, a marca da virtude se tornava visível através do domínio do sujeito sobre si, o que assegurava socialmente o direito de exercer o poder sobre os outros. A ética se sustentava numa estética da existência baseada no bom uso dos prazeres, regulados pela temperança (Foucault, 1984). A influência do pensamento grego se mostra presente até hoje através do juramento de Hipócrates. Não por acaso, o Conselho Federal de Medicina declara expressamente que a profissão médica é a mais sublime das profissões, por sua característica sacerdotal e pelo tipo de caráter apresentado pelos médicos: abnegação, sacrifício e interesse humanitário (CFM, 2007, p. 21). Mas, diante da queda contemporânea desses ideais em nossa sociedade, como os sujeitos respondem a essas mudanças? Como situam sua relação com a profissão?

Muitas vezes, esta psicanalista escutou depoimentos de sujeitos que perderam a sustentação que anteriormente encontravam na sociedade ou em sua família, encorajando-os no exercício da profissão que tradicionalmente exige abnegação e capacidade sublimatória. Nos tempos atuais, a mentalidade social se mostra voltada para admirar e desejar o crescente rendimento financeiro, e a alta qualidade de vida. Razão pela qual Lipovetsky observa que "a expressão 'viver para o próximo' (que antes era a expressão do ideal de virtude, em sua forma mais requintada) tornou-se máxima de segunda ordem, algo que, no fundo, já não se considera necessário inculcar nos filhos". O autor prossegue observando que, já no fim da década de 80 , quatro em dez norte-americanos se definiam como cínicos, e que somente $17 \%$ dos estudantes franceses consideravam o egoísmo um vício intolerável, bem abaixo das questões suscitadas pela pobreza (19\%), solidão (25\%) e intolerância (38\%). Ele conclui essa observação sobre a "era do pós-dever" constatando a demolição, pela base, da moralidade (Lipovetsky, 2005, p. 107).

\section{Sobre o caráter}

Surgem, cada vez mais, manifestações que evidenciam sujeitos orientados por novos tipos de caráter, que consideramos ser distante do caráter ético e moral tradicional, que se orienta pelo ideal do eu. Coelho dos Santos (2005) lembra que Freud moldou sua teoria do caráter a partir da formulação sobre o superego: este se consolida, com maior ou menor consistência, ao término da construção edípica, através da internalização da lei paterna. O caráter, portanto, depende da formação bem-sucedida do superego: "quanto mais afastado dele se está, menos caráter se tem" (Coelho dos Santos \& Azeredo, 2005, p. 86). Por outro lado, os autores observam que os tempos 
atuais trouxeram uma forte modificação nos princípios morais que organizavam a sociedade vitoriana. Na modernidade, esta organização social estava baseada na identificação à figura paterna e à sua autoridade. Na contemporaneidade, houve um verdadeiro desmoronamento do lugar social que sustentava o pátrio poder, desestabilizando as figuras tradicionais de autoridade - entre elas, as do sacerdote e do médico. Novos sintomas estão surgindo, como a obesidade mórbida, compulsões de todos os tipos, e outros. Verificamos inclusive sua manifestação na relação dos sujeitos com o trabalho, entre os "workaholics".

Também pude constatar, através de depoimentos sobre a prática profissional de médicos contemporâneos, a presença do funcionamento predominantemente narcísico entre sujeitos que exigem serem tratados como exceção - seguindo a referência freudiana sobre esse tipo especial de caráter, por ele nomeado em 1916. Diferentemente dos outros dois tipos de caráter também apresentados no seu texto (típicos de uma forma de organização baseada na figura paterna forte que serve ao ideal do eu), o processo de formação do caráter dos sujeitos que exigem serem tratados como exceções não implica na exigência interna de recusa ao gozo (Coelho dos Santos \& Azeredo, 2005, p. 78). Na contemporaneidade, estaríamos diante de sujeitos que não se obrigam a fazer uma contenção de suas exigências pulsionais, anteriormente determinada pela formação dominante do ideal do eu. Escutei queixas de médicos dirigidas a jovens que começam a vida profissional requerendo prerrogativas que são tradicionalmente concedidas aos mais antigos, indicando a nova mentalidade que vem se introduzindo nas relações de trabalho: vigora a exigência de um gozo imediato, sem o preço da renúncia comum aos médicos. Anteriormente, se concedia algumas prerrogativas ao profissional que havia pago esse preço durante longos anos de sacrifício pessoal no trabalho. Por exemplo, a escolha de não trabalhar em feriados especiais, como o natalino, costumava ser feita pelos que já haviam muitas vezes ficado longe dos familiares nesta data e os plantões em fins de semana eram habitualmente destinados aos novatos. Mas agora, muitas equipes ficam desfalcadas com a recusa generalizada em encontrar profissionais dispostos fazer tais concessões, e as equipes precisam contar apenas com a boa vontade daqueles que se caracterizam por assumir o perfil tradicional do médico missionário.

\section{Uma mudança no perfil profissional de médicos contemporâneos}

Cada vez mais raros, nem por isso os médicos com espírito missionário são mais respeitados ou valorizados: os depoimentos colhidos de profissionais, muitos deles amargurados com a falta de solidariedade dos colegas - ou com o desrespeito de pacientes - revelam que, diferentemente do que acontecia em tempos passados, a sociedade não remunera ou prestigia a dedicação profissional da mesma maneira como viam acontecer com seus antecessores, familiares ou mestres. De um gestor hospitalar, escutei que o tempo de existência desse perfil profissional está se esgotando: a nova mentalidade organizacional exige um novo tipo de profissional, voltado para a produtividade (mais atendimentos em menos tempo), para o uso de tecnologia de ponta vendida no mercado, 
aceitando a submissão a regras impostas pelos planos de saúde, e menor expectativa de poder e autoridade no hospital. A saúde virou um negócio e o profissional precisa agora se adaptar às exigências do mercado. Aliado à entrada da ideologia neoliberal no campo da saúde, o sujeito em busca de satisfação imediata é um profissional muito diferente daquele que trabalha orientado por um ideal humanístico ou religioso.

Pude, portanto, verificar a existência de um choque de mentalidades entre os profissionais que se identificam a um perfil orientado pelo ideal do eu, que nomeio aqui como missionários, e os que, confrontados ao imperativo do gozo mercenário (eu ideal), são comandados pelos efeitos da ideologia agora dominante, alterando as características do comportamento ético que orientam tradicionalmente a relação profissional entre médicos. O conflito entre diferentes mentalidades foi observado através de pesquisa com médicos que atuam em 2 hospitais no estado do Rio de Janeiro, e que deu sustentação à tese de doutorado sobre o sintoma profissional do Burnout nesta categoria profissional (Cunha, 2015).

Apresento minha tese: o Burnout é uma resposta subjetiva presente entre os sujeitos que vivem o conflito entre as duas mentalidades, que se contrapõem. No mundo contemporâneo verificamos o crescimento de um modo de subjetivação propício ao surgimento do caráter narcisista, o que exige ser tomado como uma exceção. Esses sujeitos estão menos aptos a se submeterem a privações ou renúncias, como as necessárias ao exercício de profissões como a medicina e enfermagem, entre outras consideradas como carreiras vocacionais. Como já foi dito, muitos sujeitos contemporâneos passaram a exercer tais profissões de uma maneira inédita, orientados agora por interesses individuais e imediatistas, deixando para trás o posicionamento tradicional de doação de si, caridade e altruísmo que aparece, por exemplo, no tradicional juramento de Hipócrates reproduzido ainda hoje, tradicionalmente, por todos os formandos de medicina ao término de sua graduação universitária.

\section{A religiosidade do perfil missionário}

Tal posicionamento se reflete no perfil missionário, na medida em que o ideal em jogo, nestes sujeitos revela uma natureza religiosa (ideais de caridade e amor ao próximo) que aparece nos depoimentos colhidos de alguns médicos. Entretanto, o perfil missionário do médico exige dele uma capacidade sublimatória que não pode ser alcançada pelos sujeitos narcisistas que encontramos em nossa pesquisa. Também a produção de um tipo de caráter altruísta não se coaduna com a mentalidade que é produzida pela ideologia neoliberal, cada vez mais presente e dominante nos espaços de atuação profissional. Foucault (1994, p. 35) mencionou o "clero da terapêutica" em seu texto sobre o nascimento da clínica, onde caracteriza a tradição em que os médicos foram tomados como "padres do corpo", em comparação aos sacerdotes, chamados de "médicos da alma". Da mesma forma, a profissão de enfermagem se inspira na imagem de Florence Nightingale, que por volta de 1860 , durante a guerra da Crimeia, mencionando atendimento a um chamado divino, 
instituiu $\mathrm{o}$ ato de cuidar como uma atividade profissional, fundando na Inglaterra o primeiro curso de enfermagem. Ainda hoje, as enfermeiras se referem a essa fundação através da lembrança da luz de vela que Florence conduzia, reproduzindo a orientação religiosa de amor ao próximo como uma iluminação de natureza divina.

Na minha experiência institucional, atuando em um hospital universitário da região serrana do Estado do Rio de Janeiro, o acompanhamento às chefias de enfermagem confirma a marcante religiosidade que orienta a vida de profissionais de enfermagem, assim como a entrega missionária de médicos ao ideal de salvar vidas. Sustentando seu desejo missionário na fantasia inconsciente de um pacto onipotente com Deus, escutei de um médico em análise uma configuração subjetiva compatível com a formação que sustenta o ideal missionário, que transforma o médico num profissional inteiramente dedicado ao cuidado da saúde alheia: sua fantasia lhe assegura o pacto que não adoecerá e que o doente será sempre o outro, aquele que lhe demanda cuidados. Esse posicionamento subjetivo é bastante encontrado neste meio profissional, conforme algumas publicações evidenciam (Meleiro, 1999; Pimentel, 2005). Os médicos, em geral, não procuram tratamento médico, não tomam vacinas, não pedem ajuda (conforme o Psychiatry on line Brazil) ${ }^{2} \mathrm{e}$ não reconhecem o risco de adoecerem, enquadrando-se na descrição do "cuidador descuidado" (Benevides-Pereira, 2002). O perfil do médico missionário traz consigo a fantasia da proteção divina, sustentando o desejo de ser um salvador.

Por outro lado, constato a tensão inerente ao choque de mentalidades sempre que esses profissionais precisam se adequar às exigências empresariais de considerarem a relação custobenefício, de evitarem as glosas dos planos de saúde, de atenderem às demandas de produtividade estabelecidas pelo contrato entre a instituição e o município, sem que sua dedicação e espiritualidade sejam valorizados em sua atuação profissional. No mundo de hoje, o Mercado se institui no lugar que pertenceu a Deus (Dufour, 2009), deslocando os valores da caridade que ainda orientam os missionários. Entretanto, não são mais esses os valores que determinam o funcionamento e a própria sobrevivência institucional. O missionário está, cada vez mais, pressionado a apresentar os indicadores quantitativos que aferem a produtividade do serviço hospitalar.

\section{O sintoma profissional}

Médicos e enfermeiras estão entre os profissionais mais afetados pela síndrome de Burnout e a literatura especializada indica que são mais afetados justamente os profissionais mais dedicados à profissão (Galam, 2008; Carlotto \& Câmara, 2008). A descrição pioneira desse sintoma profissional, feita pelo psiquiatra americano Freudenberger (1974), revela que os médicos afetados pelo fenômeno por ele observado eram voluntários que atuavam sem remuneração numa clínica alternativa, sendo bastante frequente entre os que atuavam em clínicas igualmente gratuitas. A doação de si ao trabalho, característica do ideal missionário, levou o autor a observar a necessidade de "um trabalho de luto para os profissionais do trabalho voluntário que perderam a crença em seus 
ideais" (Freudenberger, 1974, p. 165). A tese aqui proposta é que a queda dos ideais que acompanha a chegada dos novos tempos - após 1968, anos que produziu mudanças culturais em várias partes do mundo -, trouxe um choque de mentalidade nas atividades exercidas pelos profissionais que elegeram trabalhar a partir de uma posição subjetiva humanística e missionária, que está em colapso no mundo contemporâneo. Foi a partir da década de 70 que pesquisadores de todo mundo começaram a encontrar o sintoma, hoje reconhecido como uma doença profissional pela Organização Mundial de Saúde (W.H.O., 2003).

Sabemos, pela orientação psicanalítica, que não há clínica do sujeito separada da clínica da civilização. Uma nova bússola assumiu, na contemporaneidade, o comando da civilização: o objeto a, mais de gozar, com sua injunção ao gozo no consumo e aposta na suposta felicidade (Miller, 2004). Os novos tempos aprofundam os efeitos que o advento da ciência moderna produziu na civilização, abalando a visão de mundo fundada no sentido religioso (Coelho dos Santos \& Lopes, 2013, p. 10) e introduzindo um novo modo de pensar e de agir. A mudança na mentalidade social, que se manifesta em todos os cenários da realidade mundial, parece ter chegado definitivamente ao espaço sagrado da relação entre o médico e a doença, ou seja, ao campo da saúde. Este se mostra a cada dia mais afetado pela ideologia do mercado. Para não permanecer na posição de vítima, os médicos brasileiros vêm denunciando, através dos órgãos de classe e do próprio Conselho Federal, as péssimas condições de trabalho e o aviltamento de sua condição profissional, que traz consequências nefastas para sua saúde.

Um estudo conduzido pelo Conselho Federal de Medicina (CFM) sobre a saúde dos médicos, publicado em 2007, reuniu informações obtidas pelas respostas de 7.700 médicos brasileiros aos questionários enviados pelo correio, em diferentes regiões de nosso país. Entre vários aspectos que foram pesquisados, o CFM constatou que a maioria dos médicos testados (57\%) apresentou algum grau preocupante de burnout, sendo que 1 em cada 10 médicos evidenciou o maior escore possível da síndrome. Ao analisar as características contemporâneas da realidade trazida pelos médicos, 0 texto observa o paradoxo: as expectativas sociais depositadas sobre os profissionais é que sejam "ricos", mesmo tendo feito a escolha profissional por vocação (CFM, 2007, p. 13). Os aspectos éticos e morais exigidos tradicionalmente dos médicos ainda são destacados pelos conselheiros, assim como o aspecto sacerdotal que está associado ao seu trabalho, como já mencionei anteriormente. São enormes as exigências e o grau de idealização que cercam a atividade médica, que exige em princípio uma posição subjetiva peculiar, uma ética religiosa de amor ao próximo que se contrasta, claramente, com as expectativas sociais acima referidas. Concluímos, portanto, que o ideal do eu na construção do perfil missionário do médico se choca com a ideologia dominante que transformou a saúde numa mercadoria, e que apregoa uma conduta individualista e consumista para os sujeitos contemporâneos, desfigurando a conduta tradicional anteriormente exigida dos indivíduos civilizados. 


\section{Uma vinheta clínica}

Um pequeno fragmento clínico de uma entrevista realizada por mim com um estudante de medicina, nesta instituição, traz mais indicações sobre o tema. O relato colhido informou que, no meio do período de graduação, o estudante se viu tomado pelos sentimentos de exaustão, desesperança, frieza (despersonalização), e ineficácia - característicos da síndrome -, a ponto de não suportar avançar nos estudos e precisar interrompê-lo para buscar atendimento clínico. Em seu depoimento, ele observa que escolheu a profissão médica imbuído do ideal de salvar vidas e de ajudar as pessoas. Vinha de uma experiência anterior, uma graduação em outra área paramédica, mas não abriu mão de entrar na faculdade de medicina mesmo que mais tardiamente, realizando assim um antigo sonho. $O$ início do curso exigiu que trabalhasse e estudasse, pois era casado e já tinha dois filhos. Essa sobrecarga se intensificou quando a intensidade da dedicação necessária ao estudo se somou à exigência de dar plantões e fazer ambulatórios em cidades vizinhas. Observou então que a necessidade de atender muitos pacientes em pouco tempo passou a ser mais premente do que o cuidado que desejava dispensar a cada paciente em cada atendimento. A tensão e o conflito entre $o$ ideal e a realidade começaram a produzir um desgaste crescente. Comentou que, nesse ritmo, cada paciente era apenas mais um da fila a ser atendido. A pressão pela produtividade e a possibilidade de acumular vários plantões em uma mesma semana o levaram a transformar sua vida numa verdadeira maratona. Ganhar dinheiro e terminar o curso sem maior atraso o levaram a acreditar que seria possível manter sua atividade sem adoecer - até o momento da estafa.

Em sua defesa, ele alega que os estudantes, em geral, começam a se sentir muito atraídos pelas oportunidades de ganhos financeiros quando entram em contato com o mercado de trabalho, e acabam deixando de lado seus ideais humanitários: "É difícil hoje em dia um médico que trabalhe de forma regulada, planejando sua vida. A gente acaba acumulando funções e trabalho, para atingir o interesse financeiro". Mais adiante: "A gente começa o curso preocupado com o bem-estar dos pacientes, querendo curar, ajudar, cuidar. Mas, com o passar do tempo, isso muda e o paciente passa a ser apenas mais um" (Depoimento de entrevista gravada, em 2015, para fins da pesquisa).

\section{Depoimentos e outros dados de pesquisa}

Outras entrevistas, realizadas com médicos já graduados, e atuando num hospital particular da cidade do Rio de Janeiro, trazem testemunhos da submissão a poderosos grupos financeiros que retiraram do médico a condição de profissional liberal e autônomo. Tradicionalmente eram os médicos que regulavam o número de atendimentos em seus consultórios, com a liberdade de determinarem o preço de sua consulta. Mas esta possibilidade vem se restringindo gradualmente a um pequeno contingente e a maioria esmagadora alega precisar acumular vários empregos para alcançar o padrão financeiro desejado. Algumas frases retiradas dos depoimentos gravados durante entrevistas realizadas no referido hospital ilustram as afirmações apresentadas neste artigo: "Houve uma mudança de como as coisas eram antigamente, o mundo cheio de ideais... a sociedade de 
consumo criou algo que leva as pessoas a acharem que podem ter tudo à mão" (Médico formado há 6 anos); "Existe um problema atual, que é a geração Y: o cara recém-formado quer ter em um, dois anos, o que você conquistou em trinta! Ele quer a satisfação imediata!" (Médico formado há 30 anos); "Há muitos que não vestem a camisa, só querem ganhar dinheiro!" (Médica formada há 7 anos); "Há médicos gananciosos interessados apenas em ganhar dinheiro e trabalhar pouco; falta valor moral, e quem sofre é o preto pobre" (Médico formado há 8 anos).

Em outra realidade cultural, estudantes norte-americanos da SUNY Upstate Medical University, em Syracuse/New York, foram submetidos a questionários com o objetivo de medir o idealismo com que ingressam no curso médico, sendo investigadas sua motivação para a escolha desta carreira, a escolha de especialidade e suas atitudes em relação ao atendimento primário em saúde (saúde pública). Foi aplicado controle estatístico para fatores como raça, etnicidade, origem rural ou urbana, gênero e estado civil, e os resultados encontrados indicaram que, já ao final do primeiro ano de estudo em medicina, seu perfil se alterava na direção de revelar maior ênfase nas preocupações com o status e rendimentos financeiros e menor ênfase no idealismo como principal fator de motivação. Em sua conclusão, os autores observaram um sugestivo declínio do idealismo, ocorrendo mais precocemente que outros estudos haviam indicado anteriormente (Morley, Roseamelia, Smith, Villarreal, 2013). Embora seja necessário considerar as diferenças culturais em jogo, os resultados desse estudo aparentemente acompanham as indicações presentes no depoimento do estudante brasileiro, sugerindo que o declínio da mentalidade tradicional que orientava o perfil missionário está se manifestando precocemente, durante o período inicial de formação universitária.

\section{Para concluir}

Retomando a pergunta inicial, considero que os argumentos apresentados neste texto me permitem afirmar que uma nova configuração do narcisismo se evidenciou na pesquisa realizada com médicos contemporâneos e que o estudo psicanalítico do Burnout revela os efeitos sintomáticos que essas reconfigurações estão produzindo. Quando o ideal dá lugar à fantasia, a forma de subjetivação dominante não encontra mais a sustentação para aparelhar o destino pulsional da sublimação.

Diante do império dos objetos e das imagens, fomentado pela lei do mercado, novos padrões de comportamento profissional estão surgindo, afetando a antiga regulação ética que organizava a relação dos médicos com a sua profissão. Um novo perfil, mercenário, surge na contemporaneidade, produzindo contraste com o perfil tradicionalmente missionário do médico. Este novo perfil indica o predomínio dos interesses individuais sobre os coletivos, a partir da exigência desses sujeitos de serem tratados como exceção. Sua atuação escapa à regra instituída tradicionalmente, de reservar aos mais antigos os direitos alcançados durante anos de sacrifícios pessoais por dedicação ao trabalho. 
As características contemporâneas do mercado de saúde estão produzindo uma nova realidade profissional que lança muitos sujeitos a um estado de esgotamento. Defendo, a partir das pesquisas teórica e de campo realizadas, que o esgotamento profissional é desencadeado, na categoria profissional dos médicos, pela queda dos valores socioculturais que sustentaram, durante séculos, sua postura profissional, afetando arranjos que tradicionalmente regulavam seu ofício. 0 choque entre a nova mentalidade e a conduta tradicional se manifesta pelo desinteresse dos primeiros em se submeterem às normas que sempre regeram as relações entre as equipes, e no desânimo dos que não mais podem se inspirar nos antigos ideais, hoje desacreditados. Nesta condição, muitos abdicam de sua posição de sujeitos e silenciam sobre seu desejo, que acaba, porém, se manifestando de maneira cifrada e enigmática no Burnout profissional.

\section{Notas:}

${ }^{1}$ Este artigo se baseia na tese de doutorado "A psicanálise aplicada ao sintoma profissional: uma abordagem do burnout entre os médicos", apresentada ao Programa de pós-Graduação em Teoria Psicanalítica do Instituto de Psicologia da UFRJ, em fevereiro de 2015 (inédita).

2 Vide o site do Psychiatry on line Brazil (parte do International Journal of Psychiatry). Recuperado de: www.polbr.med.br em 05 de outubro de 2011, de onde foram extraídos os dados referidos.

\section{Referências Bibliográficas}

Benevides-Pereira, A. M. T. (2002). Burnout: o processo de adoecer pelo trabalho. Burnout: quando o trabalho ameaça o bem-estar do trabalhador (pp. 21-91). São Paulo: Casa do Psicólogo.

Carlotto, M \& Câmara, S. (2008, abr. a jun.). Análise da produção científica sobre a síndrome do burnout no Brasil. Revista PSICO, 39(2), 152-158.

Coelho dos Santos, T. (2016). Reconfigurações do imaginário na contemporaneidade. Resumo do grupo de pesquisa coordenado por Tania Coelho dos Santos no XVI Simpósio da ANPEPP em Maceió.

Coelho dos Santos, T. \& Azeredo, F. A. M. (2005, jul. a dez.). Um tipo excepcional de caráter. Psyché, IX(16), 77-95. São Paulo.

Coelho dos Santos, T. \& Cunha, L. H. C. S. (2013). A saúde dos corpos: entre o ideal missionário e a lógica de mercado). In Freire, A. B. (Org.), O corpo e suas vicissitudes. Rio de Janeiro: 7Letras.

Coelho dos Santos, T. \& Lopes, R. G. (2013). Psicanálise, ciência e discurso. Rio de Janeiro: Cia de Freud.

Conselho Federal De Medicina. (2007). A saúde dos médicos do Brasil. ISBN 978-85-87077-13-4.

Cunha, L. H. C. S. (2015). A psicanálise aplicada ao sintoma profissional: uma abordagem do burnout entre médicos. (Tese de doutorado). Retirado da base de dados da UFRJ.

Cunha, L. H. C. S. (nov. 2015 a abr. 2016). Entre missionários e mercenários: um estudo sobre o caráter manifesto no campo profissional contemporâneo da medicina. Revista aSEPHallus de 
Orientação Lacaniana, 11(21), 32-41. Disponível em www.isepol.com/asephallus. doi: 10.17852/1809- 709x.2019v11n21p32-41.

Dufour, D.-R. (mai. a out. 2015). A pleonexia, o que é? Revista aSEPHallus de Orientação Lacaniana, 1020), 24-38. Disponível em www.isepol.com/asephallus. doi: 10.17852/1809709x.2019v10n20p24-38.

Dufour, D.-R. (2009). O divino mercado: a revolução cultural liberal. Rio de Janeiro: Companhia de Freud.

Foucault, M. (1984). História da sexualidade 2: o uso dos prazeres. Rio de Janeiro: Edições Graal.

Foucault, M. (1994). O nascimento da clínica. Rio de Janeiro: Forense Universitária.

Freud, S. (1980a). Três ensaios sobre a teoria da sexualidade. Edição standard brasileira das obras psicológicas completas de Sigmund Freud (Vol. 7). Rio de Janeiro: Imago Editora (Trabalho original publicado em 1905).

Freud, S. (1980b). Caráter e erotismo anal. Edição standard brasileira das obras psicológicas completas de Sigmund Freud (Vol. 9). Rio de Janeiro: Imago Editora (Trabalho original publicado em 1908).

Freud, S. (2010a). Introdução ao narcisismo. Introdução ao narcisismo: ensaios de metapsicologia e outros textos (Vol. 12, pp. 13-50). São Paulo: Companhia das Letras (Trabalho original publicado em 1914).

Freud, S. (1986). Pulsiones y destinos de pulsión. Obras completas de Sigmund Freud (Vol. 14, pp. 107-134). Buenos Aires: Amorrortu Editores (Trabalho original publicado em 1915).

Freud, S. (2010b). Alguns tipos de caráter encontrados na prática psicanalítica. Introdução ao narcisismo: ensaios de metapsicologia e outros textos (Vol. 12, pp. 253-286). São Paulo: Companhia das Letras (Trabalho original publicado em 1916).

Freudenberger, H. J. (1974). Staff burnout. Journal of Social Issues, 30(1), 159-165.

Galam, E. (2008, 17 de abr.). Dossier Burn Out. Concours Medical, tome 130, (pp. 394-406). Recuperado de www.fmc31200.free.bibliotheque/burnout.pdf.

Lacan, J. (1988). O seminário, livro 7: a ética da psicanálise. Rio de Janeiro, Jorge Zahar Ed. (Trabalho original publicado em 1959-1960).

Lipovetsky, G. A. (2005). A sociedade pós-moralista: o crepúsculo do dever e a ética indolor dos novos tempos. São Paulo: Editora Manole.

Meleiro, A. M. A. S. (1999). O médico como paciente. São Paulo: Lemos-Editorial.

Miller, J.-A. (2006). La experiencia de lo real en la cura psicoanalítica. Buenos Aires: Paidós.

Miller, J.-A. (2004). Uma fantasia. Conferência proferida no IV Congresso da AMP, em Comandatuba, Brasil.

Morley, C. P.; Roseamelia, C.; Smith, J. A.; Villarreal, A. (2013). Decline of medical student idealism in the first and second year of medical school: a survey of pre-clinical medical students ato ne 
institution. Medical Education on line, 18(1). doi: 10.3402/meo.v.1810.21194. Disponível em: http://dx.doi.org/10.3402.21194.

Pimentel, D. (2005). O sonho do jaleco branco: saúde mental dos profissionais da saúde. Aracaju: Fundação Oviedo Teixeira/Sociedade Médica de Aracaju.

World Health Organization. (2003). Statement on the burnout syndrome among physicians.

European Forum of Medical Associations. Germany.

Citacão/Citation: Cunha, L. H. C. S. (mai. a out. 2017). Reconfigurações do narcisismo entre profissionais de saúde contemporâneos: o que o estudo psicanalítico sobre o Burnout tem a nos dizer sobre isso? Revista aSEPHallus de Orientação Lacaniana, 12(24), 17-30. Disponível em www.isepol.com/asephallus. doi: 10.17852/1809-709x.2019v12n24p17-30.

Editor do artigo: Tania Coelho dos Santos.

Recebido/Received: 05/10/2017 / 10/05/2017.

Aceito/Accepted: 18/10/2017 / 10/18/2017.

Copyright: (C) 2013 Associação Núcleo Sephora de Pesquisa sobre o moderno e o contemporâneo. Este é um artigo de livre acesso, que permite uso irrestrito, distribuição e reprodução em qualquer meio, desde que o autor e a fonte sejam citados/This is an open-access article, which permites unrestricted use, distribution, and reproduction in any medium, provided the author and source are credited. 